DOI: https://doi.org/10.15688/lc.jvolsu.2019.3.1

UDC 340.1:330

LBC 67.021

\title{
LAW AS THE BASIS OF INFRASTRUCTURE SUPPORT OF THE DIGITAL ECONOMY AND TECHNOLOGY OF THE INTERNET OF THINGS
}

\author{
Agnessa O. Inshakova \\ Volgograd State University, Volgograd, Russian Federation
}

\begin{abstract}
Annotation. The introductory article of the editor-in-chief traditionally serves as a prologue to the theme of the next issue of the journal, which in this issue is designated as "The Legal Regulation of the Digital Economy in the Russian Federation: Difficulties and Prospects of the Sectoral Development". The author substantiates the relevance of the chosen topic and connects it, first of all, with the comprehensive processes of socio-economic transformation of the Russian state, its innovative development, informatization of society, digitalization of the national economy and electronics, both domestic and cross-border relations of business structures and each individual. It is noted that the transition to the electronic economy requires the systematic and purposeful rethinking of the models of existing social relations in various spheres of social life - economic, political, cultural and others, in order to form the legal regulation system that adequately reflects the changed conditions of civil circulation when using information and communication technologies. The theoretical and practical problems of the digital economy development as well as the factors which predetermined them are listed. The main socio-economic transformations, the development of which is due to the digital transformation of society and which influenced the choice of the research presented in the main theme of the issue in the light of the identified priorities of the legal support of the studied processes, are called. A brief review of the scientific papers under the heading "the main theme of the issue" is made; the reader's attention is focused on the main results obtained by the authors.

Key words: social and economic transformations of the Russian state, innovative development, digital economy, information society, information technologies, digital technologies, the Internet of things, electronization of public life, digitalization of entrepreneurial activity.

Citation. Inshakova A.O. Law as the Basis of Infrastructure Support of the Digital Economy and Technology of the Internet of Things. Legal Concept, 2019, vol. 18, no. 3, pp. 6-11. (in Russian). DOI: https://doi.org/ 10.15688/lc.jvolsu.2019.3.1
\end{abstract}

УДК $340.1: 330$

ББК 67.021

\section{ПРАВО КАК ОСНОВА ИНФРАСТРУКТУРНОГО ОБЕСПЕЧЕНИЯ ЦИФРОВОЙ ЭКОНОМИКИ И ТЕХНОЛОГИИ ИНТЕРНЕТА ВЕЩЕЙ}

\section{Агнесса Олеговна Иншакова}

Волгоградский государственный университет, г. Волгоград, Российская Федерация

Аннотация. Вступительная статья главного редактора традиционно выполняет функцию пролога к теме очередного выпуска журнала, которая в данном номере обозначена как «Правовое регулирование цифровой экономики в РФ: сложности и перспективы отраслевого развития». Автор обосновывает актуальность выбранной темы и связывает это прежде всего со всеобъемлющими процессами социально-экономических 
преобразований Российского государства, его инновационным развитием, информатизацией общества, цифровизацией национальной экономики и электронизацией как внутригосударственных, так и трансграничных связей предпринимательских структур и каждого отдельно взятого человека. Отмечается, что переход к электронной экономике требует систематического и целенаправленного переосмысления моделей сложившихся общественных отношений в различных сферах общественной жизни - экономической, политической, культурной и др. с целью формирования системы правового регулирования, адекватно отражающей изменившиеся условия гражданского оборота при использовании информационно-коммуникационных технологий. Перечисляются теоретические и практические проблемы развития цифровой экономики, а также предопределившие их факторы. Называются основные социохозяйственные преобразования, развитие которых обусловлено цифровой трансформацией общества и которые повлияли на выбор научных исследований, представленных в главной теме номера в свете выявленных приоритетов правового обеспечения изучаемых процессов. Делается краткий обзор научных статей рубрики «Главная тема номера», акцентируется внимание читателя на основных результатах, полученных авторами.

Ключевые слова: социально-экономические преобразования Российского государства, инновационное развитие, цифровая экономика, информационное общество, информационные технологии, цифровые технологии, Интернет вещей, электронизация общественной жизни, дигитализация предпринимательской деятельности.

Цитирование. Иншакова А. О. Право как основа инфраструктурного обеспечения цифровой экономики и технологии Интернета вещей // Legal Concept = Правовая парадигма. $-2019 .-$ T. 18, № 3. - C. 6-11. - DOI: https://doi.org/10.15688/lc.jvolsu.2019.3.1

Выбор главной темы очередного номера журнала «Legal Concept $=$ Правовая парадигма»- «Правовое регулирование цифровой экономики в РФ: сложности и перспективы отраслевого развития» - обусловлен процессами цифровизации национальной экономики.

Потребление и экспорт информационных продуктов и услуг становится неотъемлемым атрибутом новой исторической фазы развития информационного общества, которое носит название «цифровая экономика». Развитие технологии Интернета вещей невозможно вне цифровой экономики. В ней доступна и распространена электронная форма предоставления товаров и оказания услуг, и активно развивается цифровое предпринимательство. Изменяющаяся архитектура современной экономики создает необходимость изменения не только структуры права, но и создания новых механизмов правового регулирования. Для многочисленных отраслей и институтов экономики в настоящее время создается правовой базис, позволяющий решать поставленные задачи, касающиеся, в том числе, сферы управления и контроля за деятельностью субъектов права. Однако существуют отдельные институты, где в силу определенных причин до настоящего времени не используются в должной мере информационные технологии, необходимые для эффективного управления современными организациями и осуществления контроля за их деятельностью.
Использование новых информационных технологий в построении экономики России позволяет интегрировать нашу страну в мировое пространство на началах конкурентоспособности, учитывая потребности всех слоев общества и нации в целом, при условии соблюдения экономической безопасности государства.

Одновременно становление и развитие цифровой экономики имеет как теоретические, так и практические проблемы, предопределенные множественными факторами: незрелостью и недостаточностью различных правовых институтов (в частности, электронный документооборот, электронная коммерция); отсутствием единого подхода в создании правового поля, обеспечивающего развитие цифровой экономики России; высокой степенью монополизма в индустрии; наличием административных барьеров в реализации интересов населения и бизнеса.

Переход к электронной экономике требует систематического и целенаправленного переосмысления моделей сложившихся общественных отношений в различных сферах общественной жизни - экономической, политической, культурной и др. с целью формирования системы правового регулирования, адекватно отражающей изменившиеся условия гражданского оборота при использовании информационно-коммуникационных технологий. 
Во-первых, цифровая трансформация общества опосредует возникновение и развитие альтернативной - электронной формы расчетов в экономике. Расчеты электронными денежными средствами, как и собственно их оборот, оказывают значимое влияние на институциональную структуру взаимодействий в финансовом секторе экономики. Так называемые электронные деньги позволяют повысить эффективность денежных функций.

Так, расчетные счета и электронные кошельки позволяют усовершенствовать процесс сбережения частных и корпоративных финансовых средств благодаря их автоматическому подсчету, снижению риска порчи и утраты, а также расширенным возможностям в области финансового планирования и прогнозирования, что в конечном итоге повышает эффективность функции сбережения. В аспекте функции платежа преимуществом электронных расчетов выступает упрощение и ускорение платежных операций, а также повышение их прозрачности и подконтрольности. В аспекте функции мировых денег электронная форма значительно упрощает международные (трансграничные) расчеты, так как позволяет автоматизировать процесс перевода валюты и устранить необходимость физического перемещения денежных средств, как в случае бумажных денег.

Таким образом, электронные расчеты стали объективной реальностью формирующегося в условиях развития Интернета вещей социума и пополнили цифровым платежным объектом перечень нового поколения объектов гражданских прав.

Во-вторых, можно констатировать параллельный процессу развития электронных расчетов и тесно взаимосвязанный с ним процесс широкомасштабного становления электронной коммерции (торговли). По сравнению с традиционной торговлей она обладает экстерриториальным характером, не привязана к географической местности и позволяет осуществлять внешнеторговую деятельность в режиме существенной экономии времени транзакций, участниками которых могут быть предприятия любых организационно-правовых форм, размеров, объемов оборота и отраслей специализации. Еще одним преимуществом формы электронной торговли является воз- можность максимального мониторинга наиболее выгодных предложений на отраслевом рынке, что позволяет принимать оптимальные потребительские решения, тем самым способствуя поддержанию «здоровой» конкуренции поставщиков (и продавцов).

Благодаря электронной торговле международное разделение труда становится еще более доступным. Внешнеторговая деятельность перестает быть прерогативой лишь крупных международных юридических лиц (транснациональных объединений) - транснациональных корпораций, многонациональных предприятий и офшорных компаний. Сторонами электронной торговой сделки все чаще становятся средние и мелкие предпринимательские структуры, а также физические лица. Для потребителей совершение покупок становится доступным в режиме реального времени в любом месте и в любое время суток, а для продавцов открывается возможность оптимизации бизнес-процессов за счет импорта и расширения рынков сбыта путем глобального экспорта. Это позволяет повысить эффективность производственно-распределительных процессов на всех уровнях хозяйственной деятельности - индивидуальном, корпоративном, региональном, национальном и глобальном.

В-третьих, создаются и все более активно используются в современной хозяйственной практике возможности по цифровизации различных бизнес-процессов в предпринимательстве. Электронный документооборот позволяет вести цифровой финансовый и налоговый учет и предоставлять отчетность государственным регуляторам, а также формировать внутрикорпоративные базы цифровых данных. С помощью цифровых технологий стороны хозяйственно-договорных отношений могут не только оформлять, но и поэтапно фиксировать отдельные, наиболее значимые факты развивающихся обязательственных отношений с контрагентами. Благодаря этому предпринимательская деятельность становится менее конфликтной. Кроме того, можно говорить об усилении принципа публичности (открытости) в сфере предпринимательства при одновременном снижении предпринимательских рисков, что согласуется с ключевыми установками и минимальными пра- 
вовыми стандартами, систематизированными в рекомендательных сводах международных организаций специальной и общей компетенций (см., например, Кодекс корпоративного управления Организации экономического сотрудничества и развития).

Также становится доступным дистанционный мониторинг и контроль производственно-распределительных процессов со стороны менеджмента бизнеса, обеспечивающий неукоснительное соблюдение корпоративных норм и стандартов. Возникает новая - электронная форма сотрудничества предпринимательских структур, позволяющая им дистанционно обмениваться знаниями и информацией, а также реализовывать инициативы по интеграции, формируя транснациональные экономические кластеры, глобальные инновационные сети и т. д.

В-четвертых, формируется система электронного правительства. Данная система позволяет государству дистанционно выполнять свои функции в отношении хозяйствующих субъектов - предпринимательских структур и населения, а также осуществлять электронное взаимодействие различных ветвей и уровней государственной власти. Благодаря этому государственные услуги становятся более доступными, а деятельность органов государственной власти - более прозрачной. В совокупности повышается эффективность государственного управления экономикой. Развивается «электронная демократия», позволяющая увеличить степень участия самих хозяйствующих субъектов в урегулировании предпринимательской деятельности и управлении собственной страной в целом. Это позволяет сделать процесс принятия решений более оперативным, а управление - эффективным. Электронная демократия в предпринимательской сфере обеспечивает хозяйствующим субъектам возможность реализовывать свои права и интересы удобным для себя способом, а также повышает прозрачность и доступность управления, снижает срок принятия решений, уменьшает документооборот, сокращает базу для коррупции.

По мере институционализации обозначенных изменений происходит переход к новому эволюционному типу социально-экономических систем - цифровой экономике. В со- временной России данный переход осуществлен в связи с принятием национальной программы «Цифровая экономика Российской Федерации», утвержденной распоряжением Правительства Российской Федерации от 28 июля 2017 г. № 1632-р. Переход к цифровой экономике открывает новые возможности для экономического роста и развития.

Полная или частичная автоматизация различных хозяйственных процессов способствует росту производительности труда в экономике и более рациональному расходованию ограниченных ресурсов. Извлечение преимуществ из «эффекта масштаба» становится доступным не только для крупных, но и для малых и средних предприятий. Благодаря снижению издержек производства (и, соответственно, себестоимости) усиливается ценовая конкуренция на отраслевых рынках, что повышает эффективность удовлетворения общественных потребностей.

В дополнение к этому в условиях цифровой экономики создаются и развиваются новые отрасли народного хозяйства, связанные с производством и распространением цифровых продуктов, не имеющих материально-вещественной формы, к примеру электронные книги, компьютерные программы, онлайнигры и многие другие. Данные отрасли позволяют не только диверсифицировать структуру ВВП, но и создавать дополнительные рабочие места (снижая уровень безработицы), а также ускорять темп экономического роста в случае, если они становятся векторами роста хозяйственных систем.

Все эти и другие вопросы редакционная коллегия сочла интересным вынести для обсуждения представителями различных отраслей права на страницы журнала «Legal Concept = Правовая парадигма».

Так, в статье «Нормативно-правовые особенности внедрения цифровой экономики в РФ» Г.Г. Егоров и И.Б. Орешкина ставят целью определение основных юридических механизмов, способствующих внедрению цифровых технологий. Авторы выделяют ключевые юридические составляющие современной цифровой экономики РФ, исследуют проблемы их становления с точки зрения как правотворческого, так и правореализационного процесса, а также форм правовой адаптации циф- 
ровых систем нового типа экономики. Определены недостатки развития нормотворчества, которые были выявлены на основе анализа данных электронных банков, позволившего обосновать необходимость правовой регламентации цифровых отношений в аспектах совершенствования норм права и правоприменительной практики в РФ. Предложен ряд мер по их устранению, среди которых: формирование нормативных условий адаптации цифровых прав для субъектов предпринимательской деятельности; введение единообразного подхода к понятию цифровых отношений и т. д.

В статье «Развитие цифровой экономики Российской Федерации и уголовное право: тенденции взаимовлияния» А.В. Денисова утверждает, что все отрасли права находятся под неизбежным воздействием окружающей социальной среды, в особенности национальной политики и экономики. В связи с этим автор исследует влияние процессов развития национальной цифровой экономики на отрасль российского уголовного права. Определяются взаимосвязи и взаимовлияющие тенденции развития. Автор изучает отечественное и зарубежное законодательство, международно-правовые акты и доктринальные мнения по проблемам взаимодействия экономической и правовой систем. Выявлены проблемы, препятствующие развитию цифровой экономики России, которые могут быть устранены с использованием уголовноправовых средств. Анализируются изъяны российского уголовного законодательства в сфере ряда общественно опасных деяний, совершаемых с использованием современных информационных технологий. Предлагаются пути криминализации ряда общественно опасных деяний, совершаемых с использованием современных информационных технологий. Выводы сформулированы с учетом традиций и опыта международного и национального правотворчества.

Н.А. Абузярова в своей статье «Цифровые технологии в трудовых отношениях» изучает появление такого вида фриланса, как дистанционный труд, который обусловил начало процесса формирования гибкого виртуального права. Автор отмечает, что в условиях появления «облачных технологий» возникает концепция «работ в облаке». Изучаются про- блемы правового регулирования цифровых технологий в трудовых отношениях. Подчеркивается необходимость обновления многих правовых норм, от которых зависят кардинальные изменения трудовых отношений в новых социальных условиях, с целью развития нестандартной и плодотворной занятости. Автор делает вывод, что трудовое законодательство, регулирующее электронные трудовые правоотношения, фрагментарно и не содержит всех элементов правового регулирования. Рекомендуется развитие законодательства об архивном деле в электронном виде, повсеместное внедрение электронных трудовых договоров, которые могут служить основой электронного кадрового делопроизводства. Кроме того, автор настаивает на том, что трудовое законодательство должно содержать положения о приравненности электронного трудового договора к письменной форме.

В статье, содержащей в себе научные изыскания в сфере банковского права, под названием «Цифровые токены в инструментарии современной внешнеторговой деятельности хозяйствующих субъектов юрисдикций БРИКС», выполненной при поддержке РФФИ, авторы А.И. Гончаров и М.В. Гончарова исследуют процессы компьютерной алгоритмизации производственных, транспортных, коммуникационных и других сфер общественной и хозяйственной деятельности. Авторы утверждают, что для современных предпринимателей возрастает ценность скорости и независимости от расстояния. В частности, речь идет о цифровых алгоритмах межсетевого взаимодействия для привлечения инвестиций. Авторы приводят статистические данные и прогнозируемые расчеты возрастания доли финансовых цифровых технологий в общем числе международных торговых расчетов в сфере внешнеэкономической деятельности. Актуальность введения правового регулирования цифровых инвестиционных токенов видится авторам в свете возрастания значения долгосрочных внешнеторговых проектов. Особый акцент в исследовании делается на интеграционном объединении БРИКС, в рамках которого формируется правовое поле, состоящее из национальных юрисдикций странучастниц, в том числе и России. Формулируются выводы по формированию правового 
А.О. Иншакова. Право как основа инфраструктурного обеспечения цифровой экономики и технологии

регулирования цифровой экономики на основе обнаруженных авторами ошибок и недоработок российского законодателя. Обосновываются рекомендации по закреплению жизнеспособных правовых конструкций в российской правовой системе, которые могут применяться всеми хозяйствующими субъектами БРИКС с целью ведения долгосрочной внешнеторговой деятельности. Утверждается, что развитие ICO-инвестиций будет ускоренно продолжаться. Прогнозируется продвижение технической «базы» рынка токенов, усиление крипто-защиты смарт-контрактов и транзакций в рамках их исполнения. Выводы и рекомендации по корректировке российских законопроектов, сделанные авторами, направлены на утверждение в самом ближайшем будущем токенов как цифровых крипто-записей на интернет-ресурсах, применяемых хозяйствующими субъектами внешнеторговых сделок
БРИКС в качестве привычных инвестиционных инструментов, подобных облигациям или акциям. Внесены предложения по улучшению инфраструктуры удаленных инвестиций в интернет-пространстве современной России. Сформулированы определения исследуемых инструментов дистанционного цифрового взаимодействия инвесторов и организаторов инвестирования долгосрочных внешнеторговых сделок хозяйствующих субъектов стран участниц БРИКС.

Описанным трансформациям права, а также факторам развития современной действительности, определяющим их неизбежность, посвящены и материалы информационных рубрик журнала, таких как «Хроника научной жизни» и «Критика и библиография», где описываются наиболее значимые тематические публикации и события, произошедшие за последнее время в мире науки.

\section{Information about the Author}

Agnessa O. Inshakova, Doctor of Sciences (Jurisprudence), Professor, Head of the Department of Civil and International Private Law (Base Department of The Southern Scientific Centre of the Russian Academy of Sciences), Volgograd State University, Prosp. Universitetsky, 100, 400062 Volgograd, Russian Federation, gimchp@volsu.ru, https://orcid.org/0000-0001-8255-8160

\section{Информация об авторе}

Агнесса Олеговна Иншакова, доктор юридических наук, профессор, заведующая кафедрой гражданского и международного частного права (базовая кафедра ЮНЦ РАН), Волгоградский государственный университет, просп. Университетский, 100, 400062 г. Волгоград, Российская Федерация, gimchp@volsu.ru, https://orcid.org/0000-0001-8255-8160 